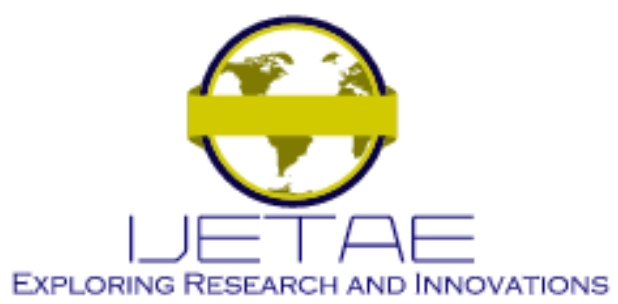

International Journal of Emerging Technology and Advanced Engineering

Website: www.ijetae.com (E-ISSN 2250-2459, Scopus Indexed, ISO 9001:2008 Certified Journal, Volume 12, Issue 02, February 2022)

\title{
Development of a Security System Based on Facial Recognition Oriented to the Management and Diversion of Criminal Attacks
}

\author{
Alejandro Boza-Chua ${ }^{1}$, Karen Gabriel-Gonzales ${ }^{1}$, Enrique Lee Huamaní ${ }^{2}$, Alexi Delgado ${ }^{3}$ \\ ${ }^{1}$ Systems engineer program, Universidad de Ciencias y Humanidades, Lima-Perú \\ ${ }^{2}$ Image Processing Research Laboratory, Universidad de Ciencias y Humanidades, Lima Perú \\ ${ }^{3}$ Mining Engineering Section, Pontificia Universidad Católica del Perú, Lima-Perú
}

\begin{abstract}
Throughout the course of time, crime and citizen insecurity continues to be one of the most harmful problems with great impacts on society, for this reason the present research work is based on the development of a security system oriented to the management and diversion of criminal attacks in Peruvian society, this being possible thanks to the help of one of the best technologies today, which is facial recognition. Likewise, together with this technology, the eXtreme Programming methodology was implemented, which, thanks to its development phases, provided different advantages for the development of this software. Consequently, it was possible to obtain positive results such as processes, innovations and viable tests for the implementation of this software in different entities of the society. The survey carried out on 17 businesses in 4 districts of northern Lima showed a $93 \%$ satisfaction rate. Finally, this research work fulfilled the needs reflected in the requirements set out at the beginning of the project, developing a viable security system.
\end{abstract}

Keywords - Citizen Security, Criminal Record, Facial Recognition, Image Recognition, XP Methodology.

\section{INTRODUCTION}

Citizen insecurity in the different entities of Peru has been on the rise since the emergence of the pandemic generated by COVID19, being a chronic, serious and complex problem. The increase in insecurity has increased in recent years throughout Latin America, this has been generated by violence and crime following the need caused by the current situation that hinders economic growth and poverty reduction.

Compared to other Latin American countries, Peru's case is particularly serious due to the fact that only $25 \%$ of these criminal actions are reported [1].
Citizen security as a national problem has become a major issue for the Peruvian community, therefore, the complications that this situation causes, come to cause and affect the quality of life of Peruvian society [2]. Robbery is one of the problems with the highest percentage in Peru according to data collected by INEI. The citizen in Peru has constant problems of insecurity, keeping all the inhabitants of different districts in anxiety and concern for their safety, both in their homes and in different social entities [3].

In order to analyze and propose a solution to this situation, research has been carried out on problems that can be addressed with facial recognition. According to the author [4], facial recognition is one of the most revolutionary technologies in the security industry, since it offers many advantages for companies that implement this type of technology within their entities, since it identifies people through an image captured by a video camera taking into account that the face is unique and its geometry reveals the patterns that identify them, so they are compared with the image that is within the database, obtaining in its conclusions that facial recognition brings great security benefits because it speeds up the arrest of criminals and missing persons.

In addition, the author [5], The FER method was used for the development of this article because it uses features of geometric shape of the regions of the face and seeks to obtain information with good accuracy of facial recognition up to $97.85 \%$ using the GCNN and concludes that more solid results can be achieved by combining facial appearance features and geometric features. 


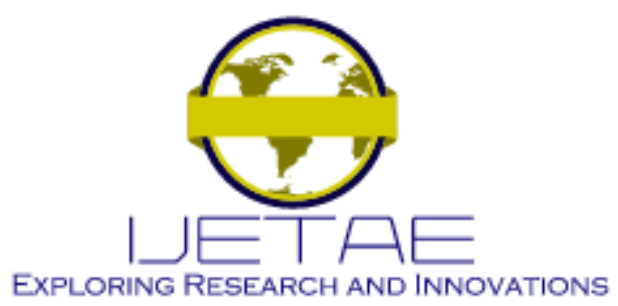

International Journal of Emerging Technology and Advanced Engineering

Website: www.ijetae.com (E-ISSN 2250-2459, Scopus Indexed, ISO 9001:2008 Certified Journal, Volume 12, Issue 02, February 2022)

Likewise, the author [6] mentions that nowadays artificial intelligence technologies are actively developing because they open up various possibilities for society, face analysis and recognition have a level within artificial intelligence and machine learning which leads to this technology being the most developed and demanded, this article seeks to compare the two popular computer vision libraries which are OpenCV and dlib, explore features, study the pros and cons of each of these libraries and deduce in which situation they are best suited, as results were obtained that the best library is OpenCV as it is the most productive and has a better performance for face detection.

Finally, the authors contributed on how the use of facial recognition can improve many aspects of society such as the arrest of criminals, anticipate criminal attacks and find missing persons because with this technology you can capture images by a video camera taking into account that the face is unique and its geometry reveals the patterns that identify them, and likewise they are compared with the image that is within the database. That is why this research work covers the implementation of a system that works with the police database with the objective of detecting people with a criminal record through facial recognition and alerting the entities of possible criminal attacks.

In view of the above, the birth of this research work is generated, taking as main objective the approach of the implementation of a software to detect people with a criminal record through facial recognition and alert possible attacks or crimes. Therefore, another of the main objectives is to demonstrate the advantage that would be the implementation of this software in different entities in addition to obtaining a greater benefit if it is able to work with the police database.

For the development of this research work, the Python programming language will be used as a tool. It is a goaloriented interpreted language with a wide dynamic semantic range, it gives a fast development as an advantage to the realization of a software system by having an extensive library at a standard level, which can be freely distributed, besides having an easy and simple syntax to understand [7]. In addition, the OpenCv library will be implemented together with this programming language. This library contains automatic learning abilities in the face of open source and artificial vision, which also facilitates the modification and use of the code [8]. On the other hand, as the last main tool and as a container of the two previous tools we have Sublime Text.
This Text editor makes the code totally readable providing an incredible work, besides giving certain advantages as the autocompletion and the selection between tabs [9] .

This research work is conformed as follows: Section II defines the methodology to be applied to the project, in addition to defining each stage in a theoretical manner. Section III describes and shows the results obtained following the steps of the methodology. Finally, section IV defines the conclusions.

\section{Methodology}

For the development of this research work, the use of the extreme programming methodology (XP) was proposed, since it is a framework oriented to the development of software engineering. In this way, it differs from traditional methodologies since it emphasizes adaptability [10]. It also reflects the sequence of principles and values that must be kept in mind and put into practice during the period of time in which the project will be developed. In addition, this methodology has 4 phases which are: planning, design, coding and testing, as shown in Fig. 1.

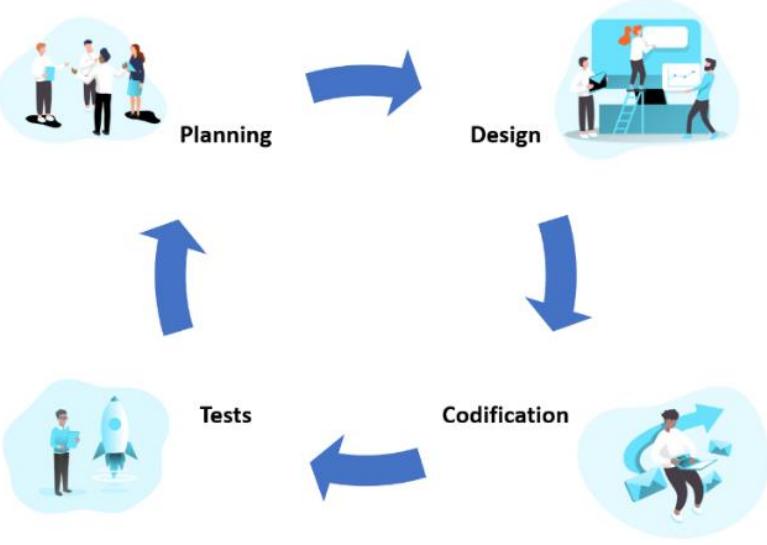

Fig. 1. Phases of the XP Methodology

As shown in Fig. 1, the XP methodology has 4 phases. First is the planning phase, where the client interacts with the development team in which the objective is to gather the necessary requirements for the development of the system. The second phase is the design, in this part the sketch of the user stories will be made according to their definition. The third phase is the coding, in this process the programming is performed where it must comply with coding standards. 


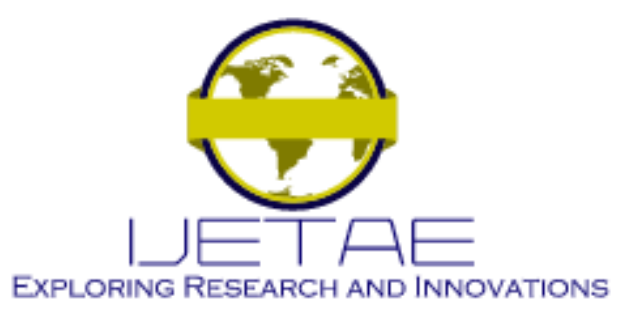

International Journal of Emerging Technology and Advanced Engineering Website: www.ijetae.com (E-ISSN 2250-2459, Scopus Indexed, ISO 9001:2008 Certified Journal, Volume 12, Issue 02, February 2022)

And finally we have the testing phase, in this final stage the necessary tests will be performed to see if the project works and meets customer requirements, previously collected in the initial phase [11].

\section{A. Planning.}

After having collected the requirements through a form made to 30 people who have some type of business oriented to the commercialization of clothing in different centers of the northern district of Lima, the following user stories could be formulated as shown in Table 1 .

\section{TABLE I}

\section{REQUIREMENTS}

\begin{tabular}{|l|l|}
\hline $\mathbf{N}^{\text {ro. }}$ & \multicolumn{1}{|c|}{ User Stories } \\
\hline 1 & $\begin{array}{l}\text { I as the administrator want the system to work with an } \\
\text { image database so that it can recognize the person through } \\
\text { the security camera. }\end{array}$ \\
\hline 2 & $\begin{array}{l}\text { I as the administrator want the system to learn from the } \\
\text { images collected previously so that it can compare and } \\
\text { identify the features of the face. }\end{array}$ \\
\hline 3 & $\begin{array}{l}\text { As administrator I want the system to classify the faces } \\
\text { captured by the camera by two colors, red color for the } \\
\text { faces that do not exist in the database and green color for } \\
\text { the people that exist in the database. }\end{array}$ \\
\hline 4 & $\begin{array}{l}\text { I as the administrator want the system to list the image } \\
\text { with which it has been compared by the camera to see if } \\
\text { the person's features match. }\end{array}$ \\
\hline 5 & $\begin{array}{l}\text { I as an administrator want the system to output the } \\
\text { percentage of similarity between the image in the database } \\
\text { and the image detected by the security camera to see how } \\
\text { likely it is that it is the correct person. }\end{array}$ \\
\hline 6 & $\begin{array}{l}\text { As the administrator I want the system to show the general } \\
\text { data of the identified person such as name, age, gender by } \\
\text { the camera to know the identification of the analyzed face. }\end{array}$ \\
\hline 7 & $\begin{array}{l}\text { as an administrator I want the system to send an alarm if a } \\
\text { person with a criminal record is identified in order to } \\
\text { provide better security. }\end{array}$ \\
\hline
\end{tabular}

\section{B. Design}

For the design of the face recognition system execution, a flow chart was determined and analyzed, which can be seen in Fig. 2. The system is designed in 3 programming blocks or processes determined by, data update, system learning and face recognition execution.

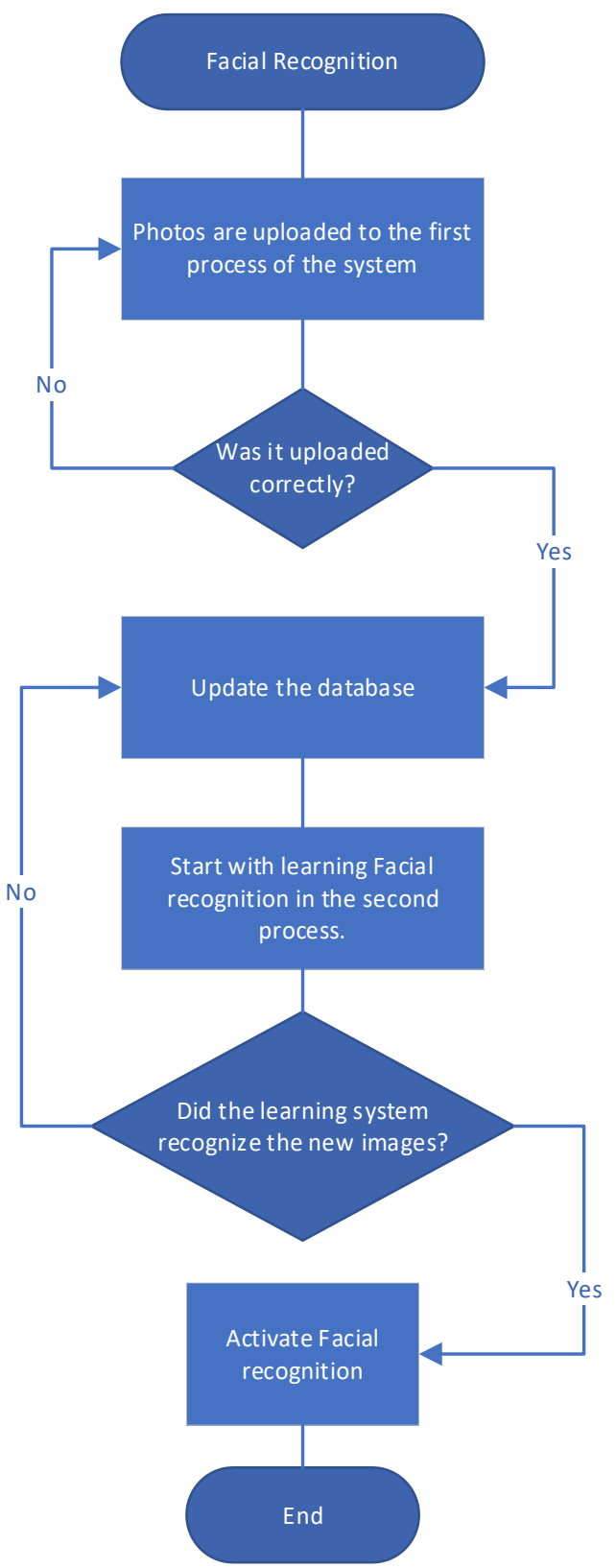

Fig. 2. Internal System Operation Flow 


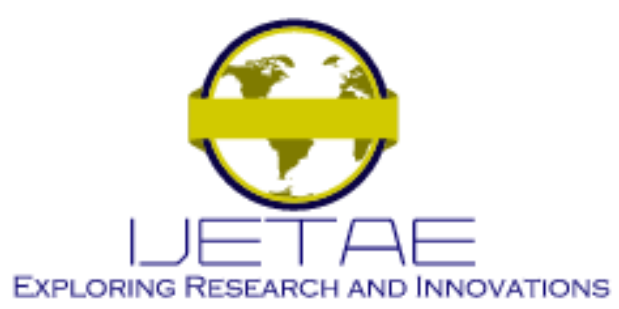

International Journal of Emerging Technology and Advanced Engineering Website: www.ijetae.com (E-ISSN 2250-2459, Scopus Indexed, ISO 9001:2008 Certified Journal, Volume 12, Issue 02, February 2022)

The operation of the system is based on the facial detection of the person who will enter the entity showing his name, after that the system evaluates his background, the facial recognition system will send an alarm if it detects that the person has a criminal record and this notice will be received by security, in case he does not, an alarm will not be sent, all this can be visualized in Fig. 3.

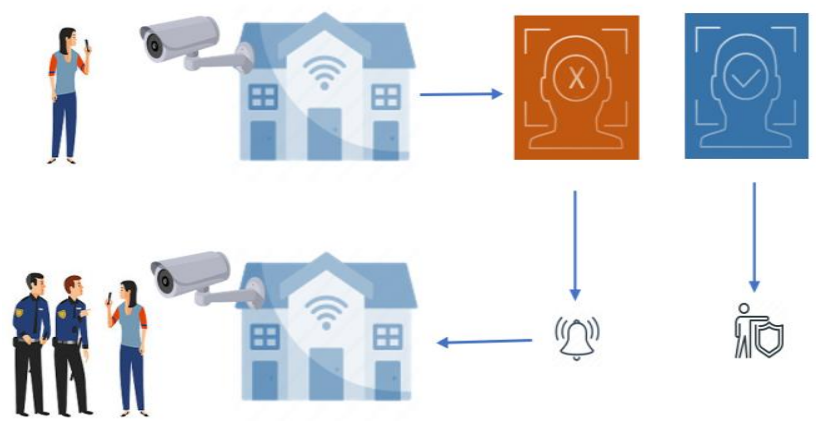

Fig. 3. External System Flow of Operation

The feasible architecture for the standardization of the security system of this project is a multilayer architecture as shown in Fig. 4, which has the functionality of distributing all the elements involved in the system based on four closed layers, these types of layers reduce the dependencies between them by only limiting the interaction between adjacent layers, in the first layer is established the interaction of the system where is the reception of the data received by the functionality of the system, which works with layer 2 being this the consumption of data through an api, as a result there is layer 3 , this layer contains the business logic where there are the system verifications. Finally, the storage layer, which is layer 4 containing the relational database. The proposed interaction on layer 4 of the database is aimed at the relationship with the police organization to improve and provide greater security, or organizations that are interested in providing or having good security.

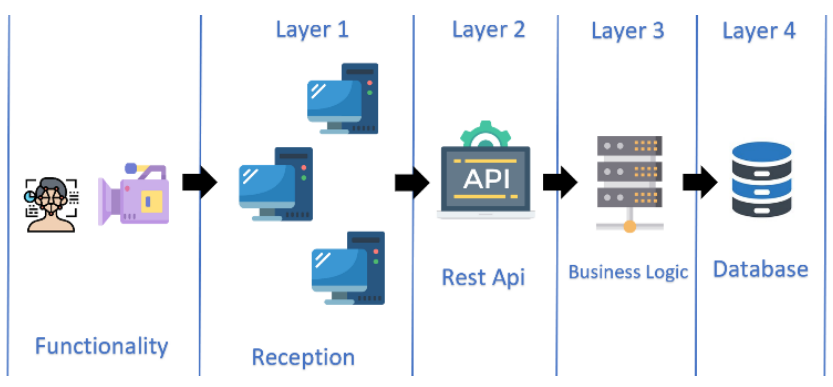

Fig. 4. Software Architecture.

C. Coding

The coding implemented for the security system was subdivided into 3 parts or processes oriented to facial recognition and system learning.

Capturing Faces: The following code will start with a counter where the frames will be read. Also, it will be resized if the size of the image or video is too large so in this process it is not necessary to press a key to store a face, therefore, the condition that was developed will help us to store 200 faces automatically with the following condition in the same size, the Pseudocode can be seen in Fig. 5.

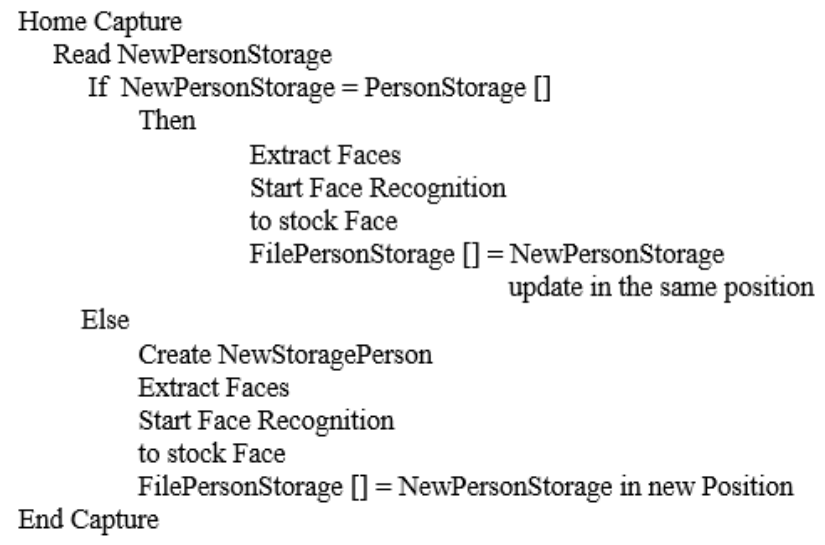

Fig. 5. Capturing Faces. 


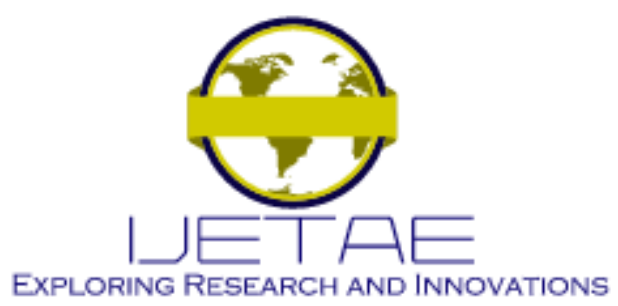

International Journal of Emerging Technology and Advanced Engineering Website: www.ijetae.com (E-ISSN 2250-2459, Scopus Indexed, ISO 9001:2008 Certified Journal, Volume 12, Issue 02, February 2022)

System Learning: In the following code the automatic learning will be developed where the system will identify the faces by image comparison, therefore in the code methods were developed to recognize and launch the image with the name of the person, this can be visualized in Fig. 6 explained in Pseudocode.

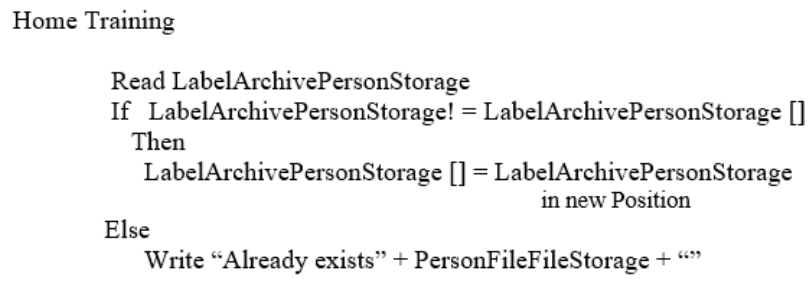

End of training

Fig. 6. System Learning

Facial Recognition: Finally, the biometric verification is developed through the comparison and the anchor points are extended obtaining a correct identification. This can be visualized in Fig. 7 explained in Pseudocode.

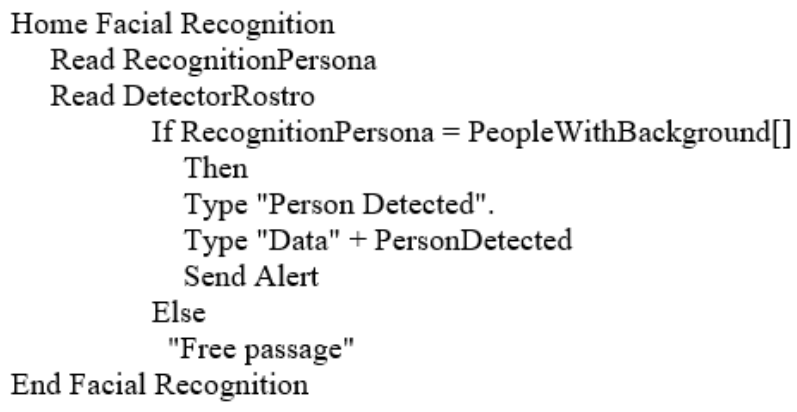

Fig. 7. Facial Recognition

\section{RESULTS}

A. Tests.

The results that will be presented below are based on the security system runs of the project, they were divided into two classifications of tests which are the free pass and the background detection.

Free pass: In this case the system performs an analysis of its storage, since this person does not have a record, it will not send an alert to the entity, so the entry process will continue as shown in Fig.8.

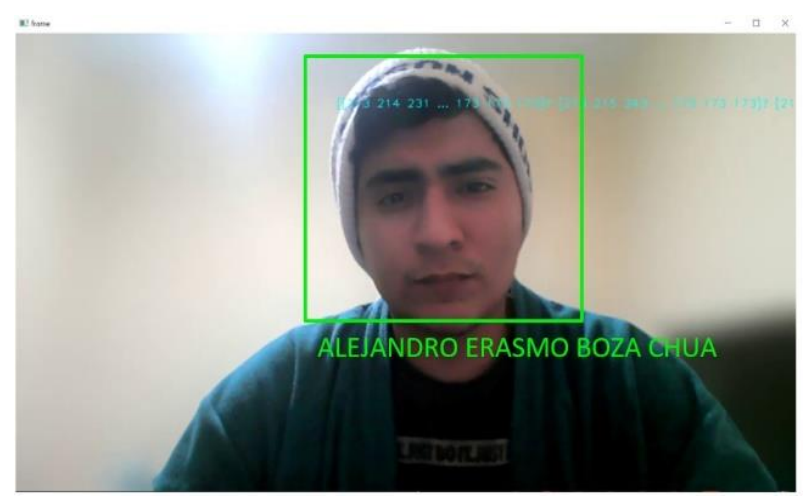

Fig. 8. Free Pass

\section{B. Satisfaction.}

In order to evaluate the degree of satisfaction obtained by the security software based on facial recognition oriented to the management and diversion of criminal attacks developed in this research work, a survey was carried out focused on companies in the commercialization area of North Lima in which 17 businesses were sampled from the following districts. Carabayllo"," Los Olivos", "Comas" and "Puente Piedra". The objective was to determine whether the security system complied with the requirements identified at the beginning of the project, as shown in Table I. Fig. 9 was structured by 5 options in which it was possible to evaluate: "Very unsatisfactory", "Very unsatisfactory", "Unsatisfactory", "Unsatisfactory" and "Unsatisfactory". "Very unsatisfactory", "unsatisfactory", "undecided", "satisfactory", "very satisfactory". In such a way that as axis (X) we have the level of satisfaction and as axis (Y) the number in which the percentage obtained by the survey was determined. By means of the diagram it was determined that the software meets the objectives of the research work.

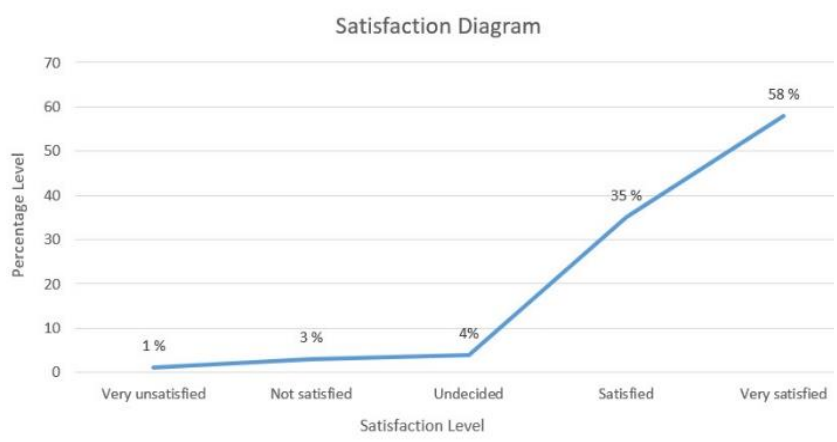

Fig. 9. Satisfaction Diagram 


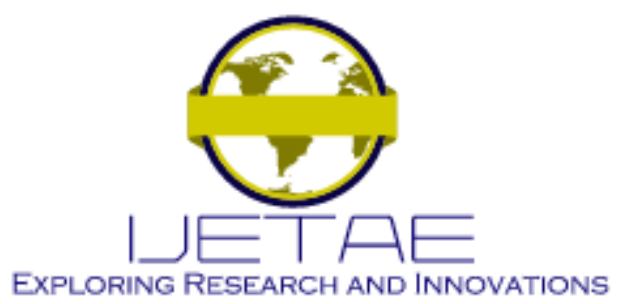

International Journal of Emerging Technology and Advanced Engineering

Website: www.ijetae.com (E-ISSN 2250-2459, Scopus Indexed, ISO 9001:2008 Certified Journal, Volume 12, Issue 02, February 2022)

\section{DISCUSSION}

\section{A. About the case study.}

Unlike other studies, oriented in the development of security systems with the aim of generating mechanisms for the prevention of possible attacks that arise in different establishments, which generate uneasiness for these businesses. According to the author [12] points out, the environment that facial recognition has within the identification of people through the characteristics, metrics of the face image and dimensions. However, it does not show evidence of the proposed being research with little visualization in the system responses, being one of the points that can be visualized in this project. Therefore, this research, unlike others, shows all the points that should be developed within the development of a security system, so an overall assessment was made where the innovation that brings this study was generated.

\section{B. Testing Process.}

In the course of development of the facial recognition system using the Python programming environment and the openCV library, it was possible to visualize possible future problems, which leads to the time used by the system to capture the features of the person through the security camera, in this process the software takes $1 \mathrm{~min}$ collecting 300 images for video which could optimize the time for the image to be collected.

\section{Innovations.}

This research brings several innovations within citizen security. For example, one of the innovative proposals is that the software developed will be able to work together with the police entity in which it will be possible to recognize people with criminal records, generating an alert to the establishment and the police station where assaults can be prevented.

\section{Technological Tools.}

In order to carry out the development of this project, several technological tools were used. One of the first tools was biometrics, this shows that it is one of the tools used to identify different individuals through facial, visual, fingerprint characteristics among others which are features that belong only to one person and can't be replaced even by identical twins.
The second tool used was Python, a versatile opensource programming language that is readable and clean when developing web applications, analyzing data, working with artificial intelligence and biometric recognition. Likewise, as a third tool, the OpenCV library was used, which worked hand in hand with the Python language since it is characterized by its open-source computer vision, machine learning and image processing. Finally, the Sublime Text 3 tool was used as a code editor, which helped in the development of the security system since it supports languages such as Python, among others, which made its creation easy and safe.

\section{CONCLUSIONS AND FUTURE WORK}

Finally, in this research work it was possible to develop a security system based on facial recognition, with the great contribution of the XP methodology, which brought several advantages to the development of this project. Also, if implemented, it will bring many benefits to society such as helping in the prevention of different criminal attacks within an entity, reducing public insecurity. On the other hand, it is mentioned that this research work could be the beginning of a great security development if it were to work together with a web page or a mobile application, making it easier for users to have access to the system. To conclude, it is necessary to indicate that with the development of this research work, the objective is to generate greater security and better quality of life in society with new technologies that meet the needs of the main problems of the population.

\section{REFERENCES}

[1] C. Insecurity, I. T. S. Incidence, and I. N. Business, "Citizen Insecurity And Its Incidence In Business Management," vol. 26, no. 52, pp. 49-58, 2018, http://dx.doi.org/10.15381/quipu.v26i52.15284.

[2] Instituto Nacional de Estadistica e Informatica., "Estadística de seguridad ciudadana," Inst. Nac. Estad. e Inform. ., vol. 2021, p. 7, 2021, [Online]. Available: https://www.inei.gob.pe/bibliotecavirtual/boletines/estadisticas-de-seguridad-ciudadana/1/.

[3] E. Sanchez, "La Inseguridad Ciudada y su Incidencia en el Delito de Robo Abravado en el Distrito de Comas 2020," p. 44, 2020, [Online]. Available: http://repositorio.usan.edu.pe/bitstream/usan/52/1/01_TI_USAN.pdf.

[4] C. D. Jaramillo, "Use of the facial recognition system to preserve public safety," vol. 20899, pp. 20-37, 2021, [Online]. Available: http://revistaseug.ugr.es/index.php/cridi/article/view/ 20899 (fecha de consulta: 13 de enero de 2020). 


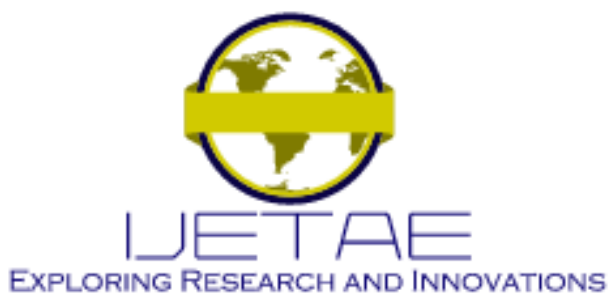

International Journal of Emerging Technology and Advanced Engineering Website: www.ijetae.com (E-ISSN 2250-2459, Scopus Indexed, ISO 9001:2008 Certified Journal, Volume 12, Issue 02, February 2022)

[5] X. Xu, Z. Ruan, and L. Yang, "Facial Expression Recognition Based on Graph Neural Network," 2020 IEEE 5th Int. Conf. Image, Vis. Comput. ICIVC 2020, pp. 211-214, 2020, doi: 10.1109/ICIVC50857.2020.9177430.

[6] [6] N. Boyko, "Performance Evaluation and Comparison of Software for Face Recognition, based on Dlib and Opencv Library," 2018 IEEE Second Int. Conf. Data Stream Min. Process., pp. 478482, 2018, doi: 10.1109/DSMP.2018.8478556.

[7] C. Sotomayor-Beltran, G. W. Z. Segura, and A. Roman-Gonzalez, "Why should Python be a compulsory introductory programming course in Lima (Peru) universities?," IEEE ICA-ACCA 2018 - IEEE Int. Conf. Autom. Congr. Chil. Assoc. Autom. Control Towar. an Ind. 4.0 - Proc., pp. 1-4, 2019, doi: 10.1109/ICAACCA.2018.8609808.

[8] K. Puthea, R. Hartanto, and R. Hidayat, "The Attendance Marking System based on Eigenface Recognition using OpenCV and Python," J. Phys. Conf. Ser., vol. 1551, no. 1, 2020, doi: 10.1088/1742-6596/1551/1/012012.
[9] E. Thiselton and C. Treude, "Enhancing Python Compiler Error Messages via Stack," Int. Symp. Empir. Softw. Eng. Meas., vol. 2019-Septe, pp. 1-12, 2019, doi: 10.1109/ESEM.2019.8870155.

[10] [A. K. Rai, S. Agarwal, and A. Kumar, "A novel approach for agile software development methodology selection using fuzzy inference system," Proc. Int. Conf. Smart Syst. Inven. Technol. ICSSIT 2018, no. Icssit, pp. 518-526, 2018, doi: 10.1109/ICSSIT.2018.8748767.

[11] J. A. Jiménez Builes, D. L. Ramírez Bedoya, and J. W. Branch Bedoya, "Metodología de desarrollo de software para plataformas educativas robóticas usando ROS-XP," Rev. Politécnica, vol. 15, no. 30, pp. 55-69, 2019, doi: 10.33571/rpolitec.v15n30a6.

[12] V. K. Sharma, "Designing of face recognition system," 2019 Int. Conf. Intell. Comput. Control Syst. ICCS 2019, no. Iciccs, pp. 459461, 2019, doi: 10.1109/ICCS45141.2019.9065373. 